http://dx.doi.org/10.4314/gjl.v6i1.67

\title{
AN ACOUSTIC INVESTIGATION OF THE DURATION OF VOWEL NASALIZATION IN GA
}

\author{
Rebecca Atchoi Akpanglo-Nartey
}

\begin{abstract}
Relationship between vowel quality and nasalization has seen a number of investigations in languages with results indicating that the duration of nasalization varies with the quality of vowel. While some of the investigations reported that greater velopharyngeal opening occurs in mid-high and high back vowels in some languages, other investigation results show that low vowels are nasalized with greater velopharyngeal opening than high vowels in some other languages. It has been argued that in vowel nasalization low vowels are preferred because low vowels have longer duration in that long vowels are more likely to be nasalized than short vowels. This study sets out to investigate the relationship between the quality of vowels and nasalization in Ga by using acoustic measures. The study makes use of four native Ga speakers' production of oral and nasal vowels in words. The words were recorded in a carrier frame and was analysed using PRAAT. The results indicate that nasal vowels have longer duration than oral vowels and the nasal part of the nasal vowel is longer in high vowels than it is in the low vowels. Generally, the nasal portion of the nasal vowel has longer duration than the oral portion of the vowel. Also, the Front vowels seem to have longer nasal portions than the back vowels. Another observation from the analysis was that the nasal vowels have higher F1 and F2 values than the oral vowel. Thus, the amount of nasalization in Ga vowels is influenced by the quality of vowel.
\end{abstract}

Keywords: Nasalization, Nasal, Duration, Acoustic, Formants, PRAAT, Vowel quality 


\section{Introduction}

The aim of this study is to acoustically analyse the oral and nasal vowels of the Ga language. The study investigates the relationship between vowel quality and nasalization in $\mathrm{Ga}$. It investigates the duration and also the quality in terms of first and second formant (F1 and F2) values of Ga oral and nasal vowels. It seeks to do a case study of how the duration of vowels affects vowel nasality. Ga is the language of the $\mathrm{Ga}$ people in Accra, the seat of the government of Ghana. It is a Kwa Language in which nasalization and tone are phonemic. It is a tone language which has an inventory of seven phonemic oral vowels. It also has five contrasting nasalized vowels which contrast meaning with changes in tone as well. Thus, Ga uses twelve phonemic vowels: /i/, /e/, /ع/, $/ \mathrm{a} /, / \mathrm{\jmath} /, / \mathrm{o} /, / \mathrm{u} /, / \tilde{\mathbf{1}} /, / \tilde{\varepsilon} /, / \tilde{\mathrm{a}} /, / \tilde{\mathrm{o}} /, / \tilde{\mathrm{u}} /$, which may be used with varying tones in utterances to create different meanings, Akpanglo-Nartey R. (2011). All the oral vowels except the mid front vowel /e/ and mid back vowel /o/, contrast with nasalized counterparts to cause lexical distinctions. The phonemic status of the nasal vowels is evident in the following pairs of Ga words:

Table 1: Phonemic status of Ga nasal vowels

\begin{tabular}{|c|c|c|}
\hline Word & $\begin{array}{l}\text { Phonetic } \\
\text { transcription }\end{array}$ & Gloss \\
\hline shi & [ 1 1́ & to pound \\
\hline shi & 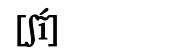 & to leave \\
\hline gbe & [gbé] & pot \\
\hline gbe & [gbéc] & ethnic mark \\
\hline ka & [ká] & to nail \\
\hline ka & [kấ] & $\begin{array}{l}\text { to stir } \\
\text { earthenware } \\
\text { bowl }\end{array}$ \\
\hline gba & [gbà] & narrated \\
\hline
\end{tabular}




\begin{tabular}{|c|c|c|}
\hline gba & [gbã̀] & married \\
\hline sho & [ & to kiss \\
\hline sho & [Shố] & to snatch \\
\hline kpo & [kpo] & knot \\
\hline kpo & [kpó́] & to save/rescue \\
\hline $\mathrm{fu}$ & [fü] & become mouldy \\
\hline $\mathrm{fu}$ & [fǜ] & to bury/smell \\
\hline
\end{tabular}

While the majority of the oral vowels may be preceded by any of the consonant phonemes of $\mathrm{Ga}$, phonemic nasal vowels may not be preceded by the consonants $/ \mathrm{p} /, / \mathrm{b} /$, $/ \mathrm{l} /, / \mathrm{d} /, / \mathrm{j} /, / \mathrm{d} /, / \mathrm{g} /, / \mathrm{kp} /$, and $/ \mathrm{w} /$. Aside the phonemic nasal vowels, there is nasalization of vowels that occur when nasal consonants in $\mathrm{Ga}$ precede vowels. In other words nasalization spreads rightwards from a nasal consonant onset to the vowel (with the exception of /a/ in yaa [yàr] 'advice'. Vowels acquire nasality when preceded by nasal consonants. On the other hand, a vowel followed by a nasal consonant may not be nasalized eg. [fley:] 'sitting on the fence', [pempeoo] 'small'.

In $\mathrm{Ga}$, vowel length is as important as the phonemes in that, duration is phonemic in both the oral and nasalized vowels. The duration of vowels in the syllable distinguishes between words lexically and grammatically in other instances. For instance, fa [fà] 'borrow'; faa [fà:] 'river or the act of borrowing'; da [dà] 'big or grow'; daa [dà] 'the act of growing'; tsa [t $\left.\int \hat{a}\right]$ 'dig out'; tsaa [t $\left.\int \hat{a}:\right]$ 'the act of digging'. Negation may also be expressed by varying the length of the vowel: for instance, be [bé] 'quarreled' but [bé:] 'did not quarrel'; ye [jé] 'eat' but [jé:] 'did not eat'.

A nasal vowel is produced by establishing an acoustic coupling between the oral and the nasal tract. This is achieved by lowering the velum to allow air flow through both the oral and the nasal tracts simultaneously. Acoustically nasalization is associated with the reduction in intensity of the first formant due to the addition of the nasal cavity in the production of the vowel. There have been many researches investigating the link between 
vowel quality and nasalization with varying results. Al-Bamerni, A. (1983) reports that, greater velopharyngeal opening occurs in mid-high and high back vowels in Gujarati and Hindi. Some of the researchers have concluded that the relationship between vowel height and nasalization is such that low vowels in French are nasalized with greater velopharyngeal opening than high vowels thus concluding that nasalization prefers low vowels over high vowels including Delvaux, P. et al. (2002).

High vowels are said to be nasalized sooner than low vowels because a small degree of velopharyngeal opening can affect the acoustic characteristics of high vowels more than low vowels. Hajek, J. et al. (2000) propose that low vowels are preferred because low vowels have longer duration in that long vowels are more likely to be nasalized than short vowels.

This paper contributes to the discussion on nasalization duration by analysing and describing the oral and nasalized vowels of the Ga language. It examines how vowel quality affects nasalization in Ga and also the duration and intensity of the nasalized vowels. The study answers the questions: how does duration of vowels differentiate between oral and nasal vowel? How does the quality of the vowel affect nasalization in $\mathrm{Ga}$ ? What is the nature of intensity in the oral and nasal vowels?

\section{The Design}

This study employs acoustic and qualitative approaches to research in the bid to describe the duration of nasalization in Ga. It uses the acoustic approach which measures physical values of the phenomenon being described. It gives a precise description of the phenomenon using frequency values of formants, intensity and duration of the sounds. The study also used the qualitative approach to research in that it describes the duration of nasalization, looking at the case of Ga.

\section{Participants}

Data was collected from two male and two female Ga native speakers of ages between 30 and 45 years. These speakers had lived most of their lives in indigenous $\mathrm{Ga}$ towns: Teshie, Ga Mashie and Tema. They have no known speech defects or hearing defects. All the speakers are literates in Ga and English languages. They all had their basic education in their native lands and went outside their lands to pursue tertiary education. 


\section{Data collection}

Monosyllabic test words made up of an onset and the oral and nasalized vowel nuclei were recorded in a frame 'ke£mo...pe', 'say ... only'. The test words were written in the Ga orthography. Table 1 above shows all the test words used in the study. A Sony IC recorder and was later acquired on PRAAT at a sampling rate of $41025 \mathrm{Khz}$. The microphone was placed at an angle of about 45 degrees and a distance of about 6 inches from the speakers' lips. The frame with test words were randomized on flash cards and speakers were given 2 mins each to familiarize themselves with the test words after which they read the frame presented to them one after another. The speakers read the test words in real sentences and also in the frame in order to help them identify the words especially since tone and nasalization are not marked in Ga orthography. The test words in the frame were said two times each.

In order to avoid variations that may be due to differences in tone, tone factor was held constant. The low tone was used in most of the test words used and where we were unable to get a minimal pair with the low tone, a pair with the high tone was used. For instance, in the case of the vowel /i/, [fí] and [fí] with high tones were included in the test words.

\section{Acoustic Analysis}

The acoustic analysis was done by generating the formant frequencies of oral and nasal vowels from different points within the utterance. The first two formant frequencies were measured from the $25 \%, 50 \%$ and $75 \%$ of the sound spectrogram. Also, the intensity of the sounds was measured at the three points within the sound signal where the formant frequency measures were taken. In addition to these, the duration of each sound was measured by enveloping the sound and measuring its length. Samples of the waveforms and spectrograms of the sounds are shown in figures one and two. 


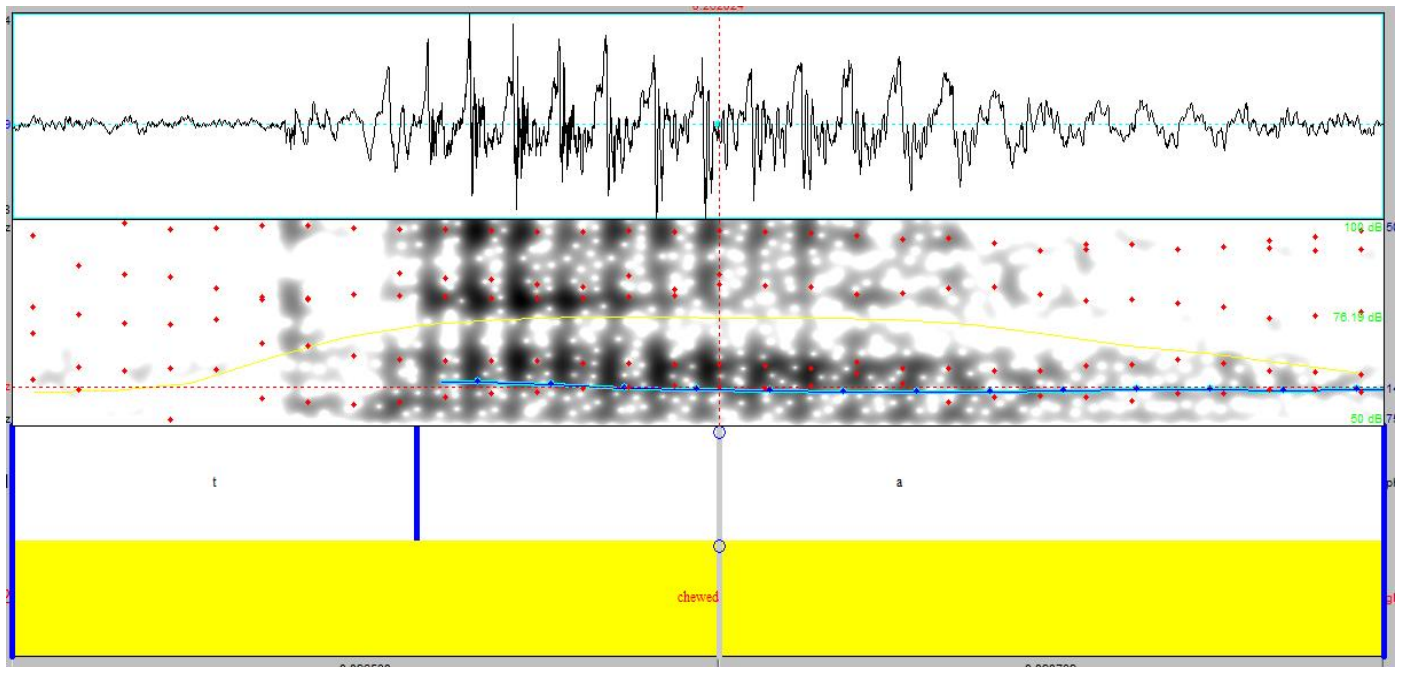

Figure 1: Waveform (top third) and Spectrogram (middle third) of [tà]which shows amplitude on the vertical axis and time on the horizontal axis in the waveform and in the spectrogram, frequency on the vertical axis and time on the horizontal axis.

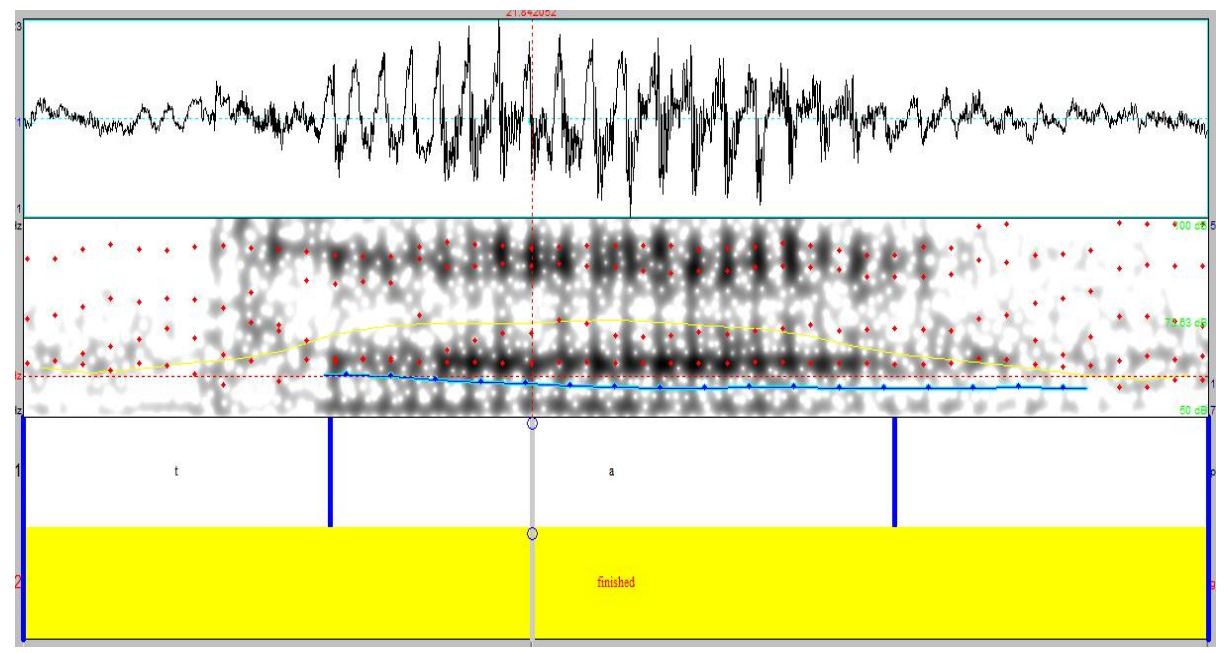

Figure 2: Waveform (top third) and Spectrogram (middle third) of [tầ] which shows amplitude on the vertical axis and time on the horizontal axis in the waveform and in the spectrogram, frequency on the vertical axis and time on the horizontal axis. 


\section{Results}

The results of this study are discussed in this section. The section discusses the results of the analysis by first of all discussing the duration results then the results of intensity analysis, and then the analysis of formant frequencies.

\subsection{Durational Analysis}

The data analysis shows that nasal vowels are consistently longer than the oral vowels for all the subjects used. This finding is similar to those of Delattre and Mannot 2009, Lovatto et al 2007, Duez 2006, Jha 1985 Whallen and Beddor 1989, and Manyah 2011. The oral /a/ measures 0.13 seconds and the nasal / $\tilde{\mathrm{a}} /$ measures 0.23 seconds for speaker RD where the onset is $/ \mathrm{b} /$; with an onset of $/ \mathrm{t} /$ the two sounds measured 0.15 and 0.20 seconds respectively; with a /f/ onset they measured 0.13 seconds and 0.18 seconds respectively. When the tones of the words were changed to the high tone, the results showed the same trend for speaker RD: with a /t/ onset /a/and /ã/sounds measured 0.17 seconds and 0.28 seconds respectively and with a /f/ onset the measures were 0.11 seconds for the oral and 0.22 seconds for the nasal. For the high tone words, the duration of the nasal vowel is almost twice the duration of the oral vowel.

The second speaker AD recorded similar trends as Speaker RD. For this speaker, the oral $/ \mathrm{a} /$ with a /b/ onset measured 0.14 seconds while the nasal / $\tilde{\mathrm{a}} /$ measured 0.25 seconds. With a /t/ onset the oral /a/ measured 0.13 seconds while the nasal $/ \tilde{\mathrm{a}} /$ measured 0.20 seconds. With a /f/ onset, the oral /a/ measured 0.13 seconds and the nasal / $\tilde{a} /$ measured 0.17 seconds. With a high tone, the oral $/ \mathrm{a} /$ with a / $/$ / onset measured 0.14 seconds while the nasal /a/ measured 0.29 seconds. With a /f/ onset the oral /a/ measured 0.11 seconds while the nasal measured 0.2 seconds. Again, the duration of the nasal vowel is twice as long as that of the oral vowels.

The duration of the oral and nasal high front vowel /i/ shows that for speaker RD the oral vowel with a /f/ onset measures 0.19 seconds while the nasal vowel measures 0.23 seconds; with a $/ \mathrm{t} /$ / onset the oral /i/ measured 0.09 seconds while the nasal /i/ measured 0.23 seconds.

Speaker AK recorded an oral /i/ with a /f/ onset that measures 0.09 seconds and a nasal /i/ which measures 0.22 seconds. With a $/ \mathrm{t} /$ onset this speaker records an oral $/ \mathrm{i} /$ of 0.09 seconds and a nasal $/ \tilde{1} /$ of 0.21 seconds. 
These measurements indicate that the nasal vowels measured for the two speakers are twice as long as their corresponding oral vowels.

Measures for the oral and nasal mid front show that nasal $/ \tilde{\varepsilon} /$ is also twice as long as the oral $/ \varepsilon /$. For speaker RD, the oral $/ \varepsilon /$ with a $/ \mathrm{gb} /$ onset measures 0.13 seconds while the nasal counterpart measures 0.24 seconds. For speaker AK, the oral $/ \varepsilon /$ with a $/ g b /$ onset measures 0.17 seconds while the nasal counterpart measures 0.21 seconds.

The oral and nasal mid back vowel show that nasal / $\tilde{\partial} /$ is also twice as long as the oral $/ \mathrm{s} /$. For speaker RD, the oral $/ \mathrm{s} /$ with a $/ \mathrm{f} /$ onset measures 0.13 seconds while the nasal counterpart measures 0.24 seconds. With a /f/ onset the oral vowel measured 0.13 seconds while the nasal measured 0.19 seconds. And with a $/ \mathrm{k} /$ onset the oral vowel measured 0.1 seconds and the nasal vowel measured 0.24 seconds.

Speaker AK recorded oral $/ \mathrm{o} /$ with a $/ \mathrm{J} /$ onset that measures 0.11 seconds while the nasal counterpart measures 0.25 seconds. With a /f/ onset the oral vowel measured 0.15 seconds while the nasal measured 0.19 seconds. And with a $/ \mathrm{k} /$ onset the oral vowel measured 0.13 seconds and the nasal vowel measured 0.24 seconds.

The study showed that the nasal cues of the vowels in all instances are relatively longer than the oral cues. The only exception to this is in / $/$ with $/ \mathrm{k} /$ and /f/ onsets where the oral cues were longer than the nasal cues. This is shown in Figure 2 below. In Figure 2 the ' $\mathrm{X}$ ' axis represents the duration while the ' $\mathrm{Y}$ ' axis represents the vowel type.

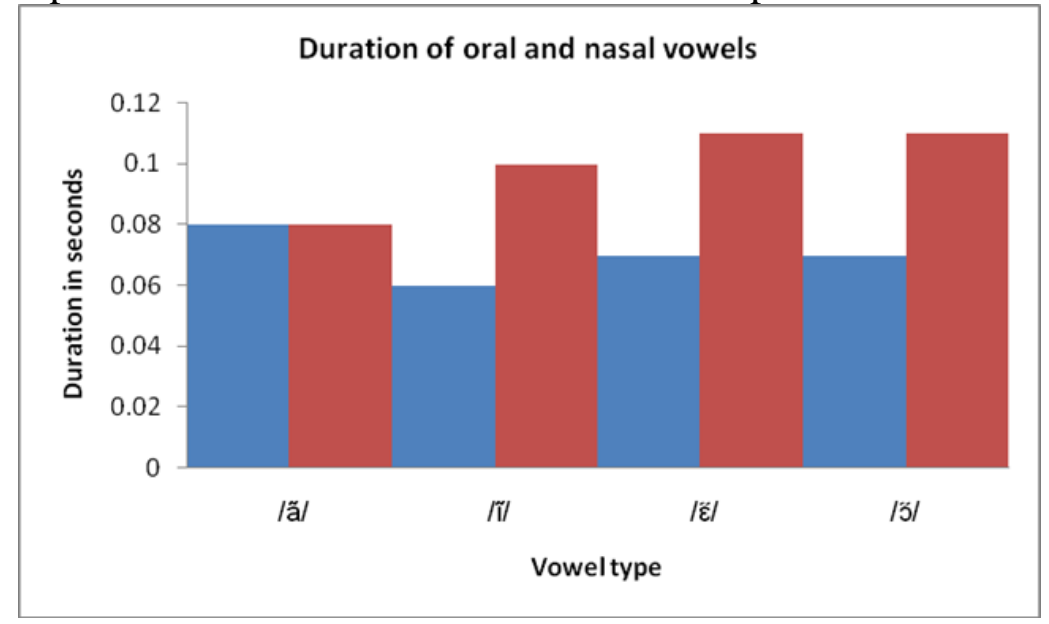

Figure 3: Duration of oral and nasal portions of vowels. The figure shows oral cue of the vowel in blue and the nasal cue in wine. The duration of sounds in seconds is shown on the vertical axis and the vowel types are shown on the horizontal axis. 
Averagely, the vowel /a/ for all the speakers shows that the nasal vowel is longer than the oral counterpart by about 0.04 seconds and in the nasal vowel, the nasal portion is longer than the oral portion of the vowel by 0.01 seconds. The vowel / $\mathrm{i} / \mathrm{shows}$ similar trends to the vowel /a/ in that the nasal vowel is longer than the oral counterpart by 0.06 seconds, the nasal portion being longer than the oral portion of the nasal vowel by 0.04 seconds. The nasal vowel $/ \tilde{\varepsilon} /$ is longer than the oral counterpart by 0.04 seconds and the nasal portion of it is longer than the oral portion by 0.04 seconds. Similarly, the nasal vowel / $\tilde{\mathrm{s}} /$ is longer than the oral vowel by 0.03 seconds and the nasal portion is longer than the oral by 0.04 seconds.

It is realized from the analysis that the duration of the nasal vowel is longest for the mid front vowel, followed by the low back vowel and the mid back vowel. Nasalization is shortest for the mid back vowel which shows the smallest variation $(0.03$ seconds) between the duration of the oral and the nasal vowel. The analysis indicates that the nasal cues are longer than the oral. The nasal duration of the low vowel is shortest (0.01 seconds) compared to the other vowels where the duration of the nasal portion is about 0.04 seconds.

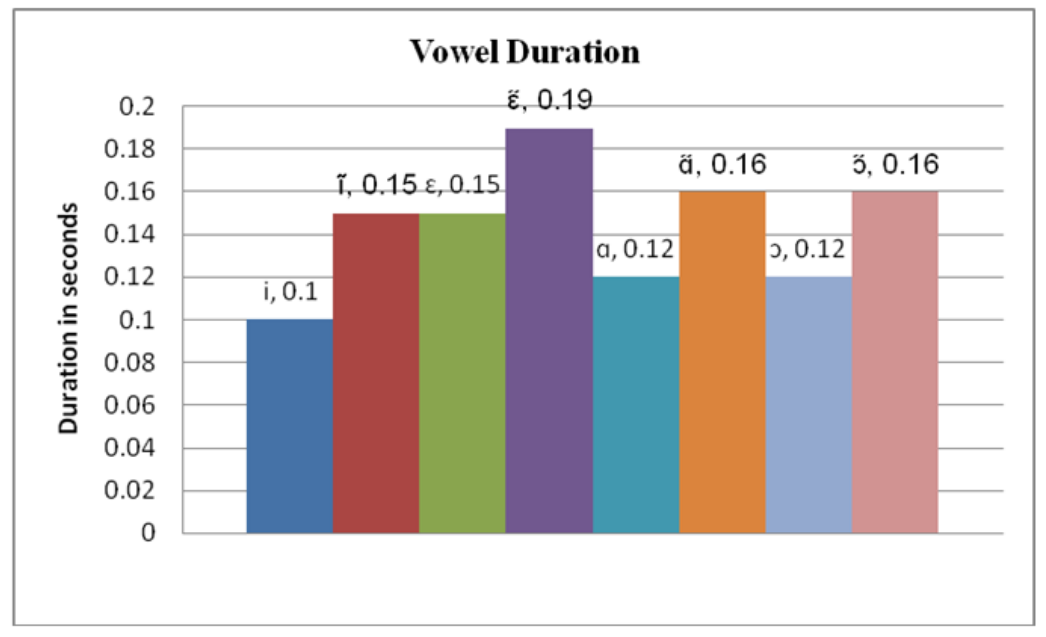

Figure 4: Average duration of oral and nasal cues of vowels. The duration of sounds is shown in seconds on the vertical axis and the vowel types are shown on the horizontal axis. 
In a Consonant Vowel (CV) environment the consonants before both the oral and the nasal vowel are relatively shorter than the vowels. The length of the consonant does not seem to be affected by the nasality of the following vowel because there are instances in the data where the consonants are equal in duration for the oral and nasal vowel: in ba [bấ] the consonant duration is 0.08 seconds; in fa [fã́] the consonant duration is 0.17 seconds. In other instances, the consonant duration is longer before the nasal vowel than before the oral vowel while in other instances the reverse is true. Thus, the relationship between nasality and consonant duration for the onset is not established in this data.

\subsection{Analysis of Intensity}

The intensity for / $\mathrm{a} /$ at the $25 \%$ point is $77 \mathrm{~dB}$. This decreased by the $50 \%$ point to $74 \mathrm{~dB}$ and to $69 \mathrm{~dB}$. The nasal started with an intensity of $78 \mathrm{~dB}$ which decreased to $75 \mathrm{~dB}$ and to $72 \mathrm{~dB}$. /i/ at the $25 \%$ point has an intensity of $77 \mathrm{~dB}$ and this came to $76 \mathrm{~dB}$ and to $75 \mathrm{~dB}$. The nasal $/ \tilde{1} /$ started with $78 \mathrm{~dB}$ and reduced to $77 \mathrm{~dB}$ and to $75 \mathrm{~dB}$. $/ \varepsilon /$ has an intensity of $81 \mathrm{~dB}$ which dipped to $79 \mathrm{~dB}$ and to $76 \mathrm{~dB}$. The nasal $/ \tilde{\varepsilon} /$ starts with $82 \mathrm{~dB}$ and fell to $81 \mathrm{~dB}$ and to $62 \mathrm{~dB}$. The sound $/ \mathrm{s} /$ at the $25 \%$ point has an intensity of $80 \mathrm{~dB}$ which fell to $78 \mathrm{~dB}$ and to $74 \mathrm{~dB}$. The nasal $/ \tilde{\partial} /$ at the $25 \%$ point measured $79 \mathrm{~dB}$ in intensity and this fell to $77 \mathrm{~dB}$ and to $71 \mathrm{~dB}$.

\subsection{Analysis of Formants}

The analysis of Formants was done by looking at the trends in the first formant frequency (F1) and then the second formant frequency (F2) of the participants. The measures were taken from the $25 \%, 50 \%$ and $75 \%$ points (i.e. The first third, the midpoint and the final third) within the utterance.

\subsubsection{F1 measurements}

For speaker RD, F1 for the oral /a/ rises gradually from $715 \mathrm{~Hz}$ through $766 \mathrm{~Hz}$ to $779 \mathrm{~Hz}$ while the nasal /ã/ started with $523 \mathrm{~Hz}$ at the $25 \%$ point of utterance and by the $50 \%$ point $\mathrm{F} 1$ had reduced to $449 \mathrm{~Hz}$ which further reduced to $367 \mathrm{~Hz}$ by the $75 \%$ point of utterance. Thus, the nasal vowel /ã/ has relatively lower F1 at the various points than the oral vowel /ã/. 
$\mathrm{F} 1$ for $/ \mathrm{i} /$ at the point $25 \%$ measured $323 \mathrm{~Hz}$ and reduced to $315 \mathrm{~Hz}$ at the $50 \%$ point and then to $281 \mathrm{~Hz}$ at the $75 \%$ point of the vowel. For the nasal counterpart $/ \tilde{1} / \mathrm{F} 1$ measured $365 \mathrm{~Hz}$ at $25 \%$ and reduced to $201 \mathrm{~Hz}$ at $50 \%$ and to $196 \mathrm{~Hz}$ at $75 \%$. The nasal of /i/ therefore has a relatively higher F1 value than the oral counterpart. It however reduced to a value lower than the oral by the end of the sound.

The vowel / $/$ / for speaker RD measured $512 \mathrm{~Hz}$ at $25 \%$ and this dipped to $498 \mathrm{~Hz}$ by the $50 \%$ and then dipped further to $426 \mathrm{~Hz}$ by the $75 \%$ point. $/ \tilde{\varepsilon} /$ measured $511 \mathrm{~Hz}$ at $25 \%$, dipped to $342 \mathrm{~Hz}$ at $50 \%$ and to $266 \mathrm{~Hz}$ at the $70 \%$ point. The nasal $/ \tilde{\varepsilon} /$ has relatively lower F1 values than the oral counterpart throughout the sound. The vowel $/ \mathrm{s} /$ is $528 \mathrm{~Hz}$ at $25 \%$ but dips like other vowels to $497 \mathrm{~Hz}$ at $50 \%$ and to $498 \mathrm{~Hz}$ at $75 \%$. / $/$ / starts with $504 \mathrm{~Hz}$ at $25 \%$, dips to $447 \mathrm{~Hz}$ at the midpoint and then $386 \mathrm{~Hz}$ at $75 \%$. The nasal $/ \tilde{\partial} /$ like the other nasal sounds has a relatively lower F1 values than the oral $/ \mathrm{o} /$.

For speaker $\mathrm{AK}, / \mathrm{a} /$ starts with $697 \mathrm{~Hz}$ at $25 \%$ then rises to $770 \mathrm{~Hz}$ at the midpoint and again rises to $779 \mathrm{~Hz}$ by the $75 \%$. The nasal / $\tilde{\mathrm{a}} / \mathrm{starts}$ with a lower $\mathrm{F} 1 \mathrm{of} 508 \mathrm{~Hz}$ at $25 \%$ and then dips to $429 \mathrm{~Hz}$ by the midpoint and dips again to $409 \mathrm{~Hz}$ at the $75 \%$ point. The figures show relatively lower F1 values for the nasal sound.

The vowel $/ \varepsilon$ / for this speaker measured $471 \mathrm{~Hz}$ at $25 \%$ but dips to $451 \mathrm{~Hz}$ by the midpoint and rises to $474 \mathrm{~Hz}$. The nasal $/ \tilde{\varepsilon} /$ measured $380 \mathrm{~Hz}$ which was reduced by the midpoint, to $365 \mathrm{~Hz}$. It again dipped to $340 \mathrm{~Hz}$ by the $75 \%$ point.

The /i/ sound measured $321 \mathrm{~Hz}$ at the $25 \%$ point and this fell to $306 \mathrm{~Hz}$ by the $50 \%$ point and then to $307 \mathrm{~Hz}$ by the $75 \%$ point of the sound. The nasal $/ \mathbf{1} /$ measured $396 \mathrm{~Hz}$ at $25 \%$ and reduced to $328 \mathrm{~Hz}$ at $50 \%$ and reduced again to $296 \mathrm{~Hz}$. The nasal $/ \overline{1} /$ unlike other nasals for speaker AK has relatively higher F1 values than the values for the oral.

Sound $/ \mathrm{s} /$ has $\mathrm{F} 1$ value of $549 \mathrm{~Hz}$ at the $25 \%$ point of the sound and the value reduced to $501 \mathrm{~Hz}$ by the midpoint of the sound. The value then increased to $529 \mathrm{~Hz}$ by the $75 \%$ point of the sound. The nasal / $/$ / started with a relatively higher $\mathrm{F} 1$ of $562 \mathrm{~Hz}$ but dips to $463 \mathrm{~Hz}$ at the midpoint and then to $411 \mathrm{~Hz}$ by the $75 \%$ point of the sound.

F1 for speaker NA, /a/ increased gradually from $661 \mathrm{~Hz}$ through $673 \mathrm{~Hz}$ at the midpoint and the value here is maintained at the $75 \%$ point in the sound. The nasal / $\tilde{\mathrm{a}} /$ started with a relatively lower $\mathrm{F} 1$ of $620 \mathrm{~Hz}$ at the $25 \%$ point of utterance and by the $50 \%$ point $\mathrm{F} 1 \mathrm{had}$ increased to $680 \mathrm{~Hz}$ which is higher than the $\mathrm{F} 1$ value of the oral $/ \mathrm{a} / \mathrm{F} 1$ further increased to $701 \mathrm{~Hz}$ by the $75 \%$ point of utterance. Thus, the nasal vowel / $\tilde{\mathrm{a}} / \mathrm{has}$ relatively higher F1 values on the average than the oral counterpart.

The /i/ vowel sound measured $379 \mathrm{~Hz}$ at the point $25 \%$ and increased to $398 \mathrm{~Hz}$ at the $50 \%$ point and then decreased to $355 \mathrm{~Hz}$ at the $75 \%$ point of the vowel. For the nasal 
counterpart $/ 1 / \mathrm{F} 1$ measured $351 \mathrm{~Hz}$ at $25 \%$ and increased $356 \mathrm{~Hz}$ at $50 \%$ and decreased again to $270 \mathrm{~Hz}$ at $75 \%$. The nasal of /i/ therefore has relatively lower F1 values than the oral counterpart.

The vowel $/ \varepsilon /$ for speaker NA measured $404 \mathrm{~Hz}$ at $25 \%$ and this increased to $530 \mathrm{~Hz}$ by the $50 \%$ and then to $605 \mathrm{~Hz}$ by the $75 \%$ point. $/ \tilde{\varepsilon} /$ measured $506 \mathrm{~Hz}$ at $25 \%$, dipped to $487 \mathrm{~Hz}$ at $50 \%$ and then to $376 \mathrm{~Hz}$ at the $70 \%$ point. The nasal $/ \tilde{\varepsilon} /$ has relatively lower $\mathrm{F} 1$ values at the $50 \%$ and $75 \%$ points of the sound than the oral counterpart but higher $\mathrm{F} 1$ at the $25 \%$.

The vowel sound $/ \mathrm{s} /$ for this speaker has $\mathrm{F} 1$ of $551 \mathrm{~Hz}$ at $25 \%$ which increases to $579 \mathrm{~Hz}$ at $50 \%$ and then to $576 \mathrm{~Hz}$ at $75 \%$. $/ \tilde{\mathrm{s}} / \mathrm{starts}$ with $584 \mathrm{~Hz}$ at $25 \%$, dips to $537 \mathrm{~Hz}$ at the midpoint and then to $453 \mathrm{~Hz}$ at $75 \%$. The nasal / $/$ / has a higher $\mathrm{F} 1$ value at $25 \%$ than the oral counterpart but has relatively lower values at the $50 \%$ and $75 \%$ points of the sound.

Speaker AJ's, /a/ starts with $\mathrm{F} 1$ of $658 \mathrm{~Hz}$ at $25 \%$ then rises to $731 \mathrm{~Hz}$ at the midpoint and again rises to $777 \mathrm{~Hz}$ by the $75 \%$. The nasal /ãa starts with a lower F1 of $589 \mathrm{~Hz}$ at $25 \%$ and then dips to $555 \mathrm{~Hz}$ by the midpoint and dips again to $414 \mathrm{~Hz}$ at the $75 \%$ point. The figures show relatively lower $\mathrm{F} 1$ values for the nasal sound.

$/ \varepsilon /$ vowel sound for this speaker measured $451 \mathrm{~Hz}$ at $25 \%$ but dips to $430 \mathrm{~Hz}$ by the midpoint and to $428 \mathrm{~Hz}$. The nasal $/ \tilde{\varepsilon} /$ measured $487 \mathrm{~Hz}$ which was reduced by the midpoint, to $477 \mathrm{~Hz}$. It again dipped to $337 \mathrm{~Hz}$ by the $75 \%$ point. At the $25 \%$ and $50 \%$ points of the sound, the nasal $/ \tilde{\varepsilon} /$ has relatively higher F1 values than the oral counterpart.

Sound /i/ has F2 of $358 \mathrm{~Hz}$ at the $25 \%$ point and this fell to $331 \mathrm{~Hz}$ by the $50 \%$ point and then increased to $377 \mathrm{~Hz}$ by the $75 \%$ point of the sound. The nasal $/ 1 /$ measured $380 \mathrm{~Hz}$ at $25 \%$ and reduced to $302 \mathrm{~Hz}$ at $50 \%$ and reduced again to $290 \mathrm{~Hz}$. The nasal / $/$ / has relatively higher F1 values at the $25 \%$ point than the F1 value for the oral.

The vowel /o/ has F1 value of $526 \mathrm{~Hz}$ at the $25 \%$ point of the sound and the value increased to $528 \mathrm{~Hz}$ by the midpoint of the sound. The value then increased again to $550 \mathrm{~Hz}$ by the $75 \%$ of the sound. The nasal / $/$ / started with a relatively lower F 1 of $507 \mathrm{~Hz}$ then increased to $527 \mathrm{~Hz}$ at the midpoint and then decreased to $460 \mathrm{~Hz}$ by the $75 \%$ point of the sound. 
Table 2: F1 Percentages for Vowels

$\begin{array}{cccc} & & \mathrm{F} 1 & \\ \text { vowel } & 25 \% & 50 \% & 75 \% \\ / \mathrm{a} / & 683 & 735 & 752 \\ / \tilde{\mathrm{a}} / & 560 & 529 & 473 \\ / \mathrm{i} / & 345 & 337 & 330 \\ / \tilde{\mathrm{i}} / & 320 & 307 & 284 \\ / \mathrm{\varepsilon} / & 484 & 475 & 483 \\ / \tilde{\varepsilon} / & 471 & 418 & 305 \\ / \mathrm{\jmath} / & 539 & 501 & 538 \\ / \tilde{\mathrm{\jmath}} / & 530 & 494 & 430\end{array}$

The average F1 values for all the speakers are plotted in Figures 5, 6, 7, and 8, which show the relationships between the oral vowels and their nasal counterparts. As shown in Figure 5 the oral /i/ vowel starts with F1 of $345 \mathrm{~Hz}$ and falls slightly to $337 \mathrm{~Hz}$ and then to $330 \mathrm{~Hz}$. The difference between the frequencies at the $25 \%$ point and the $50 \%$ point is $8 \mathrm{~Hz}$ and the difference between the $75 \%$ point and the $50 \%$ point is $7 \mathrm{~Hz}$. With the nasal vowel /i// however the difference between the $50 \%$ and the $25 \%$ point is $13 \mathrm{~Hz}$ and the difference between the $75 \%$ point and the $25 \%$ point is $23 \mathrm{~Hz}$. Therefore, the F1 for the nasal vowel has a steeper slope compared with that of the oral vowel /i/. Generally, the nasal vowel shows lower F1 values than the oral vowel. Thus, nasalizing the vowel /i/ is an indication of lowered $\mathrm{F} 1$.

The vowel / $/$ / shows similar F1 movement through the utterance as /i/. The oral vowel shows $\mathrm{F} 1$ of $484 \mathrm{~Hz}$ and about $9 \mathrm{~Hz}$ higher at the $25 \%$ point than the $50 \%$ point and the $50 \%$ point shows about $8 \mathrm{~Hz}$ lower value than the value at the $75 \%$. Like the $/ \mathrm{i} /$ and $/ \mathrm{i} /$ vowels, the nasal $/ \tilde{\varepsilon} /$ has lower F1 values than the oral $/ \varepsilon /$ but the difference at the $75 \%$ point is even bigger $(78 \mathrm{~Hz})$ and this is shown in the slope of F1 chart in Figure 6.

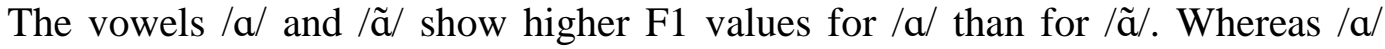
starts with $683 \mathrm{~Hz}$ the nasal / $/ \tilde{a} / \mathrm{starts}$ with $560 \mathrm{~Hz}$, a difference of $123 \mathrm{~Hz}$ at the $25 \%$ point. At the $50 \%$ point, there is a difference of $206 \mathrm{~Hz}$ and a difference of $279 \mathrm{~Hz}$ at the $75 \%$ point. While the oral vowel F1 is rising for this vowel, it is falling for the nasal counterpart. 
The vowels $/ \mathrm{\rho} /$ and $/ \tilde{\partial} /$ show higher $\mathrm{F} 1$ values for $/ \mathrm{\rho} /$ than for $/ \tilde{\mathrm{o}} /$. Whereas $/ \mathrm{\rho} /$ starts with $539 \mathrm{~Hz}$ the nasal $/ \tilde{\mathrm{o}} / \mathrm{starts}$ with $530 \mathrm{~Hz}$, a difference of $9 \mathrm{~Hz}$ at the $25 \%$ point. At the $50 \%$ point, there is a difference of $7 \mathrm{~Hz}$ and a difference of $8 \mathrm{~Hz}$ at the $75 \%$ point. The nasal vowel $\mathrm{F} 1$ falls through the utterance with a difference of $36 \mathrm{~Hz}$ between the $25 \%$ and $50 \%$ and a difference of $64 \mathrm{~Hz}$ between the $50 \%$ and the $75 \%$ points. This shows a significant drop as shown in Figure 8.

The values for F1 between the oral vowels and their nasal counterparts show that the nasal vowels have lower values than the oral vowels. Also, the nasal vowels have F1 values which fall significantly through the $25 \%, 50 \%$ and $75 \%$ points in the vowels.

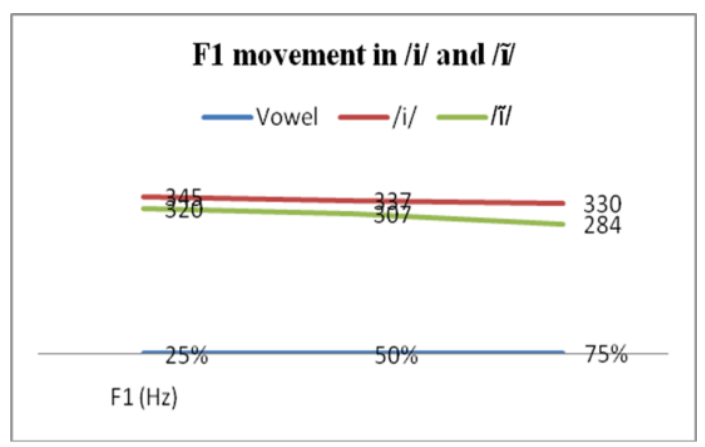

Figure 5: $\mathrm{F} 1$ for $/ \mathrm{i} /$ and $/ \mathrm{i} /$

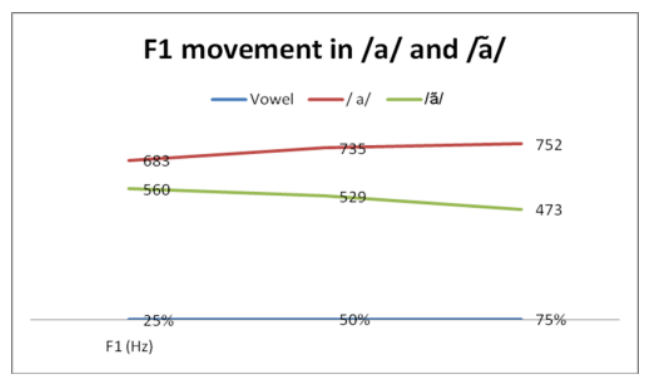

Figure 7: F1 for /a/ and /ã/

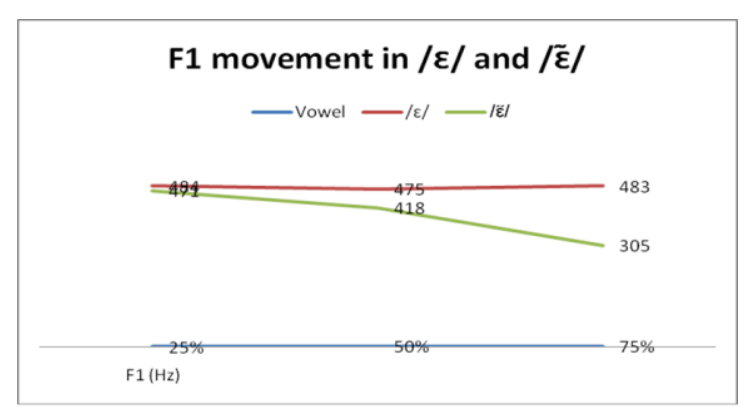

Figure 6: $\mathrm{F} 1$ for $/ \varepsilon /$ and $/ \tilde{\varepsilon} /$

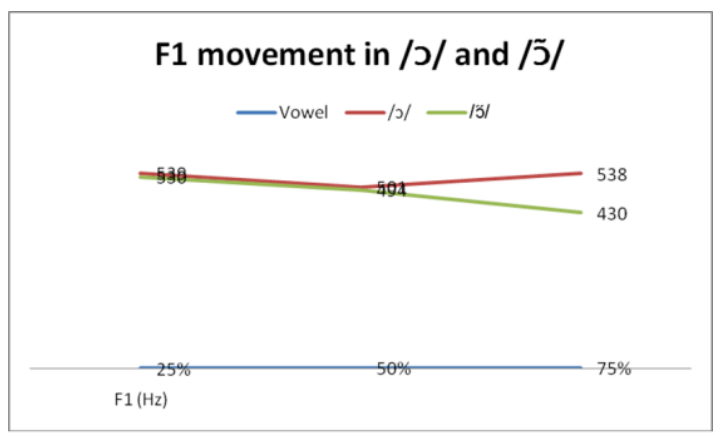

Figure 8: $\mathrm{F} 1$ for $/ \mathrm{o} /$ and $/ \tilde{\mathrm{o}} /$ 


\subsubsection{F2 Measurements}

The Second Formant (F2) frequency for each of the sounds under discussion was measured from the first third, halfway and the last third of the sound signal.

Speaker RD, F2 for the oral /a/ rises gradually from $1585 \mathrm{~Hz}$ through $1657 \mathrm{~Hz}$ to $1724 \mathrm{~Hz}$ while the nasal /ã/ started with $1372 \mathrm{~Hz}$ at the $25 \%$ point of utterance and by the $50 \%$ point $\mathrm{F} 1 \mathrm{had}$ reduced to $1340 \mathrm{~Hz}$ which further reduced to $1327 \mathrm{~Hz}$ by the $75 \%$ point of utterance. Thus, the nasal vowel / $\tilde{\mathrm{a}} /$ has relatively lower F2 at the $25 \%, 50 \%$ and $75 \%$ points than the oral vowel/a/.

The vowel /i/ at the point $25 \%$ measured $1916 \mathrm{~Hz}$ and reduced to $1722 \mathrm{~Hz}$ at the $50 \%$ point and then to $1717 \mathrm{~Hz}$ at the $75 \%$ point of the vowel. For the nasal counterpart $/ 1$ / F2 measured $1873 \mathrm{~Hz}$ at $25 \%$ and reduced to $1569 \mathrm{~Hz}$ at $50 \%$ and to $1492 \mathrm{~Hz}$ at $75 \%$.

The vowel / $\varepsilon$ / for speaker RD measured $2049 \mathrm{~Hz}$ at $25 \%$ and this rose to $2078 \mathrm{~Hz}$ by the $50 \%$ and then dipped to $2047 \mathrm{~Hz}$ by the $75 \%$ point. $/ \tilde{\varepsilon} /$ measured $1995 \mathrm{~Hz}$ at $25 \%$, rose to $2027 \mathrm{~Hz}$ at $50 \%$ and to $1678 \mathrm{~Hz}$ at the $70 \%$ point. The nasal / $\tilde{\varepsilon} /$ has relatively lower F2 values than the oral counterpart throughout the sound.

The vowel $/ \mathrm{s} /$ is $528 \mathrm{~Hz}$ at $25 \%$ but dips like other vowels to $497 \mathrm{~Hz}$ at $50 \%$ and to $498 \mathrm{~Hz}$ at $75 \%$. / $/$ starts with $1266 \mathrm{~Hz}$ at $25 \%$, dips to $1163 \mathrm{~Hz}$ at the midpoint and then $1269 \mathrm{~Hz}$ at $75 \%$. The nasal /õ/ has a relatively higher F2 values than the oral. It starts with $1420 \mathrm{~Hz}$ at $25 \%$ and is reduced to $1260 \mathrm{~Hz}$ at $50 \%$ is increased again to $1413 \mathrm{~Hz}$ at the $75 \%$ point.

For speaker AK, F2 for /a/ starts with $1423 \mathrm{~Hz}$ at $25 \%$ then rises to $1522 \mathrm{~Hz}$ at the midpoint and decreases to $1468 \mathrm{~Hz}$ by the $75 \%$. The nasal / $\tilde{\mathrm{a}} /$ starts with a lower F2 of $1353 \mathrm{~Hz}$ at $25 \%$ and then dips to $1253 \mathrm{~Hz}$ by the midpoint and rises to $1283 \mathrm{~Hz}$ at the $75 \%$ point.

The vowel / $\varepsilon /$ measured $1829 \mathrm{~Hz}$ which was raised by the midpoint, to $2030 \mathrm{~Hz}$. It again increased to $2225 \mathrm{~Hz}$ by the $75 \%$ point. The nasal $/ \tilde{\varepsilon} /$ for this speaker measured F2 of $1633 \mathrm{~Hz}$ at $25 \%$ which dips to $1436 \mathrm{~Hz}$ by the midpoint and rises to $1521 \mathrm{~Hz}$.

F2 for the vowel /i/ measured $1925 \mathrm{~Hz}$ at the $25 \%$ point and this fell to $1919 \mathrm{~Hz}$ by the $50 \%$ point and then to $1886 \mathrm{~Hz}$ by the $75 \%$ point of the sound. The nasal $/ 1 /$ measured $1935 \mathrm{~Hz}$ at $25 \%$ and reduced to $1872 \mathrm{~Hz}$ at $50 \%$ and reduced again to $1849 \mathrm{~Hz}$ at $75 \%$.

The vowel / $/$ / has F2 value of $1392 \mathrm{~Hz}$ at the $25 \%$ point of the sound and the value reduced to $1265 \mathrm{~Hz}$ by the midpoint of the sound. The value then increased to $1355 \mathrm{~Hz}$ by the $75 \%$ of the sound. The nasal / $/$ / started with a relatively higher F2 of $1430 \mathrm{~Hz}$ but dips to $1423 \mathrm{~Hz}$ at the midpoint and then to $1362 \mathrm{~Hz}$ by the $75 \%$ point of the sound. 
F2 for speaker NA, /a/ increased gradually from $1328 \mathrm{~Hz}$ through $1368 \mathrm{~Hz}$ at the midpoint to 1392 at the $75 \%$ point in the sound. The nasal /ã/ started with a relatively lower $\mathrm{F} 2$ of $1143 \mathrm{~Hz}$ at the $25 \%$ point of utterance and by the $50 \%$ point F2 had increased to $1147 \mathrm{~Hz}$. F2 further increased to $1305 \mathrm{~Hz}$ by the $75 \%$ point of utterance.

The vowel /i/ measured $1328 \mathrm{~Hz}$ at the point $25 \%$ and increased to $1367 \mathrm{~Hz}$ at the $50 \%$ point and then increased to $1392 \mathrm{~Hz}$ at the $75 \%$ point of the vowel. For the nasal counterpart $/ 1 / \mathrm{F} 2$ measured $2257 \mathrm{~Hz}$ at $25 \%$ and decreased to $2172 \mathrm{~Hz}$ at $50 \%$ and decreased again to $2054 \mathrm{~Hz}$ at $75 \%$. The vowel $/ \varepsilon$ / for speaker NA measured $1291 \mathrm{~Hz}$ at $25 \%$ and this increased to $1622 \mathrm{~Hz}$ by the $50 \%$ and then to $1666 \mathrm{~Hz}$ by the $75 \%$ point.

$/ \tilde{\varepsilon} /$ measured $1463 \mathrm{~Hz}$ at $25 \%$, increased to $1713 \mathrm{~Hz}$ at $50 \%$ and then to $1775 \mathrm{~Hz}$ at the $70 \%$ point. The vowel $/ \mathrm{o} /$ is $1035 \mathrm{~Hz}$ at $25 \%$ but dipped to $899 \mathrm{~Hz}$ at $50 \%$ and then to $888 \mathrm{~Hz}$ at $75 \%$. $/ \tilde{\mathrm{J}} / \mathrm{starts}$ with $979 \mathrm{~Hz}$ at $25 \%$, increases to $1038 \mathrm{~Hz}$ at the midpoint and then dips to $907 \mathrm{~Hz}$ at $75 \%$.

Speaker AJ's, /a/ starts with F2 of $1392 \mathrm{~Hz}$ at $25 \%$ then rises to $1488 \mathrm{~Hz}$ at the midpoint and again rises to $1537 \mathrm{~Hz}$ by the $75 \%$ point. The nasal /ãa starts with a lower F2 of $1284 \mathrm{~Hz}$ at $25 \%$ and then rises to $1361 \mathrm{~Hz}$ by the midpoint and rises again to $1435 \mathrm{~Hz}$ at the $75 \%$ point. The figures show relatively lower F2 values for the nasal sound.

The F2 for vowel $/ \varepsilon /$ for this speaker measured $1630 \mathrm{~Hz}$ at $25 \%$ which rises to $1772 \mathrm{~Hz}$ by the midpoint and then to $1790 \mathrm{~Hz}$ by the $75 \%$ point. F2 for the nasal $/ \tilde{\varepsilon} /$ measured $1701 \mathrm{~Hz}$ at the $25 \%$ point and this rose to 1899 by the midpoint, and to $2044 \mathrm{~Hz}$ by the $75 \%$ point.

The vowel /i/ F2 measured $1992 \mathrm{~Hz}$ at the $25 \%$ point and this fell to $1988 \mathrm{~Hz}$ by the $50 \%$ point and then to $1937 \mathrm{~Hz}$ by the $75 \%$ point of the sound. The nasal $/ \tilde{1} / \mathrm{F} 2$ measured $2114 \mathrm{~Hz}$ at $25 \%$ and reduced to $2035 \mathrm{~Hz}$ at $50 \%$ and then rose to $2050 \mathrm{~Hz}$.

The vowel / $/$ / has F2 value of $969 \mathrm{~Hz}$ at the $25 \%$ point of the sound and the value decreased to $918 \mathrm{~Hz}$ by the midpoint of the sound and then to $917 \mathrm{~Hz}$ by the $75 \%$ point of the sound. The nasal /õ/ started with a relatively lower F2 of $1033 \mathrm{~Hz}$ then decreased to $976 \mathrm{~Hz}$ at the midpoint and then to $950 \mathrm{~Hz}$ by the $75 \%$ point of the sound.

Table 3: F2 Vowel Percentages

\begin{tabular}{lccc} 
& \multicolumn{3}{c}{ F2 } \\
Vowel & $25 \%$ & $50 \%$ & $75 \%$ \\
/a/ & 1507 & 1509 & 1530 \\
/ã/ & 1288 & 1275 & 1337
\end{tabular}




$\begin{array}{llll}/ \mathrm{i} / & 1973 & 1923 & 1999 \\ / \mathrm{i} / & \mathbf{1 8 4 5} & \mathbf{1 8 7 5} & \mathbf{1 8 2 9} \\ / \varepsilon / & \mathbf{1 7 7 4} & \mathbf{1 8 7 5} & \mathbf{1 9 3 2} \\ / \tilde{\varepsilon} / & 1698 & 1769 & 1705 \\ / \mathrm{\jmath} / & 1166 & 1061 & 1107 \\ / \tilde{\jmath} / & 1216 & 1174 & 1158\end{array}$

The average F2 values for all the speakers are plotted in Figures 9, 10, 11, and 12, which show the relationships between the oral vowels and their nasal counterparts. Figure 9 shows F2 values for the oral /i/ vowel which starts with $1973 \mathrm{~Hz}$ and falls slightly to $1923 \mathrm{~Hz}$ and then rises to $1999 \mathrm{~Hz}$. The F2 for the nasal vowel $/ \mathrm{i} /$ is lower at the $25 \%$ $(1845 \mathrm{~Hz})$ and this rose slightly to $1875 \mathrm{~Hz}$ and then fell again to $1829 \mathrm{~Hz}$. Generally, the nasal vowel shows lower F2 values than the oral vowel. Thus, nasalizing the vowel /i/ brings about lowered F2.

The vowel / $/$ / shows similar F2 movement through the utterance as /i/. The oral vowel shows $\mathrm{F} 2$ of $1774 \mathrm{~Hz}$ at the $25 \%$ point and this rose to $1875 \mathrm{~Hz}$ and then dipped to $1829 \mathrm{~Hz}$ at the $75 \%$ point. Like the /i/ and /i// vowels, the nasal / $\tilde{\varepsilon} /$ has significantly lower F2 values than the oral $/ \varepsilon /$ and this is clear in Figure 10.

Figure 11 shows the graph F2 values for the vowels /a/ and /ã/. As is shown the oral /a/ has higher F2 values than the nasal/ã/. Whereas /a/ starts with $1507 \mathrm{~Hz}$ the nasal starts with $1288 \mathrm{~Hz}$, a difference of $219 \mathrm{~Hz}$ at the $25 \%$ point. At the $50 \%$ point, there is a difference of $234 \mathrm{~Hz}$ and a difference of $293 \mathrm{~Hz}$ at the $75 \%$ point between the oral and the nasal.

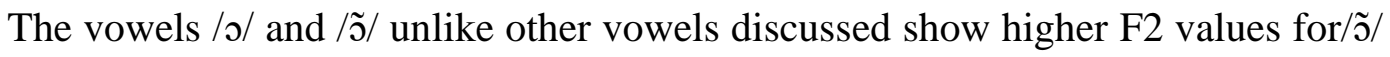
than $/ \mathrm{s} /$. Whereas $/ \mathrm{s} /$ starts with $1166 \mathrm{~Hz}$ the nasal $/ \tilde{\jmath} /$ starts with $1216 \mathrm{~Hz}$, a difference of $50 \mathrm{~Hz}$ at the $25 \%$ point. At the $50 \%$ point, there is a difference of $113 \mathrm{~Hz}$ and a difference of $51 \mathrm{~Hz}$ at the $75 \%$ point.

The values for F2 between the oral vowels and their nasal counterparts show that the nasal vowels have lower values than the oral vowels except with the vowels $/ \mathrm{s} /$ and /ั̃/. 
Akpanglo-Nartey: An Acoustic Investigation of The Duration of Nasalization in Ga

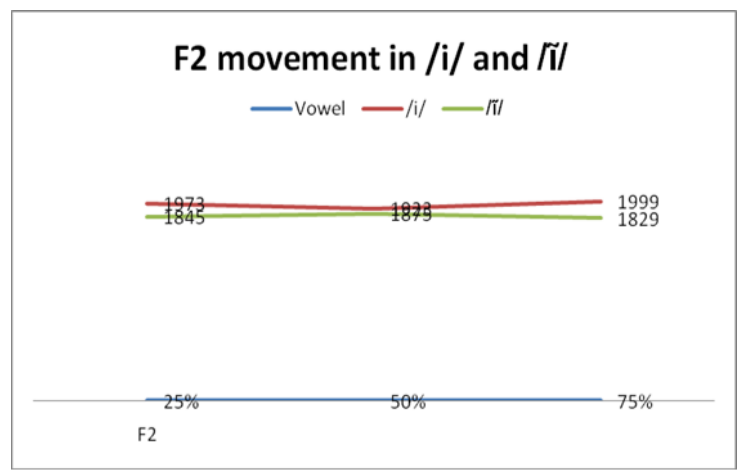

Figure 9: F2 of /i/ and /i/

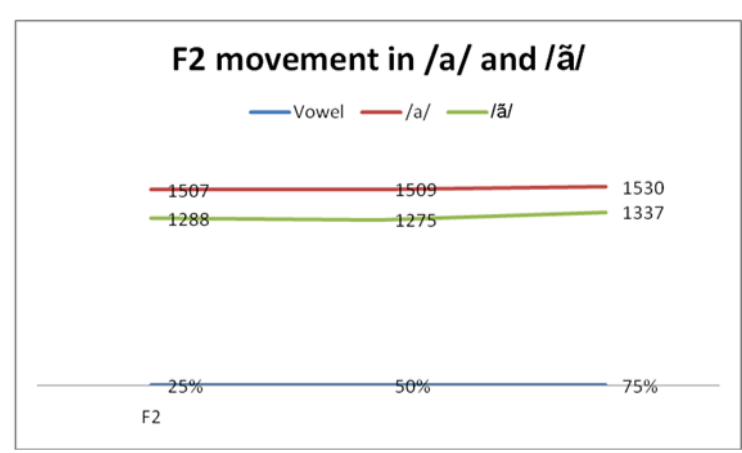

Figure 11: F2 of /a/ and / $\tilde{a} /$

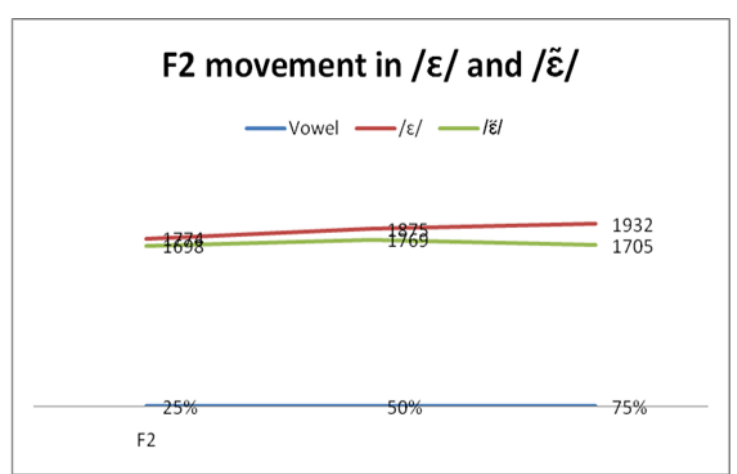

Figure 10: $\mathrm{F} 2$ of $/ \varepsilon /$ and $/ \tilde{\varepsilon} /$

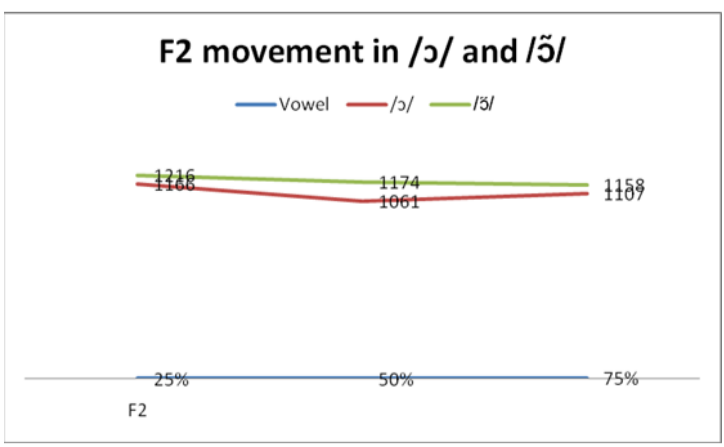

Figure 12: F2 of /o/ and / $/$ /

\section{Discussion and Conclusion}

This study aimed at investigating the duration effect of nasalization in Ga vowels. It is also to find how the nasal vowels differ acoustically from the oral vowels in terms of frequency and intensity. The finding of the study is to be a contribution to discussions on vowel nasalization on languages.

\subsection{The Duration of Nasalization}


Although observations made from the results of this study are solely on absolute values, it is evident that nasalization in all instances is very long in the sense that the nasal cues of the vowels are relatively longer than the oral cues. The only exception to this is in $/ \tilde{\mathrm{o}} /$ with $/ \mathrm{k} /$ and $/ \mathrm{f} /$ onsets where the oral cues were longer than the nasal cues. The nasal vowel / $\tilde{\mathrm{a}} /$ is longer than the oral counterpart by about 0.04 seconds and in the nasal vowel, the nasal portion is longer than the oral portion of the vowel by 0.01 seconds. Similarly, the nasal vowel is longer than the oral counterpart by 0.06 seconds, the nasal portion being longer than the oral portion of the nasal vowel by 0.04 seconds. The nasal vowel $/ \tilde{\varepsilon} /$ is longer than the oral counterpart by 0.04 seconds and the nasal portion of it is longer than the oral portion by 0.04 seconds. Similarly, the nasal vowel / $/$ / is longer than the oral vowel by 0.03 seconds and the nasal portion is longer than the oral by 0.04 seconds.

It is realized from the analysis that the duration of the nasal vowel is longest for the high front vowel, though the high front vowel is not the longest vowel produced by the respondents. In fact, the high front vowel seems to be the shortest vowel produced i.e. 0.1 seconds. The mid front vowel is relatively longer than all the other vowels $(0.15$ seconds) but nasalization in this vowel is not as long as that of the high front vowel. The duration of nasalization of the mid front vowel is second to that of the high front vowel in length and is followed the low central vowel /a/. Nasalization is shortest for the mid back vowel which shows the smallest variation (30 milliseconds) between the duration of the oral and the nasal vowel. The oral and nasal portions of the nasal vowels show that the nasal portions are longer than the oral. The nasal duration of the low vowel is shortest (10 milliseconds) compared to the other vowels where the duration of the nasal portion is about 0.04 seconds and this is in contrast with what Hajek, J. and Maeda, S. (2000) and Delvaux P. et al (2002) reported in French that low vowels are more likely to be nasalized.

In a Consonant Vowel (CV) environment the consonant before both the oral and the nasal vowel are relatively shorter than the vowels. The length of the consonant does not seem to be affected by the nasality of the following vowel because there are instances in the data where the consonants are equal in duration for the oral and nasal vowel: in ba [bã] the consonant duration is 0.08 seconds; in fa [fã] the consonant duration is 0.17 seconds. In other instances, the consonant duration is longer before the nasal vowel than before the oral vowel while in other instances the reverse is true. Thus, the relationship between nasality and consonant duration for the onset is not established in this data. 
The intensity values from the data indicate that the nasal vowels have slightly higher intensities than the oral vowels except for the mid back vowel where the oral vowel has a relatively higher intensity than the nasal. In all cases, the intensity was high at the $25 \%$ and by the $75 \%$ point the intensity is reduced. Thus, intensity is a cue to the oral/nasal contrast in the vowels of $\mathrm{Ga}$.

The values for F1 between the oral vowels and their nasal counterparts show that the nasal vowels have lower values than the oral vowels. Also, the nasal vowels have F1 values which fall significantly through the $25 \%, 50 \%$ and $75 \%$ points in the vowels. This is also true for the F2 values of all the vowels except the mid back vowel. This indicates that while the nasalized front vowels are made less front than the oral counterparts, the nasalized mid back vowel is made less back than the oral counterpart. Also, the nasal vowels are made with a slightly higher tongue height than their oral counterparts. 


\section{References}

Akpanglo-Nartey, R. 2011. Vowels of GaDangme: A Spectrographic Study.VDM Verlag Dr. Muller GmbH \& Co.KG. Saarbrucken, Germany.

Al-Bamerni, A. 1983. Oral, Velic and Laryngeal Coarticulation across Languages. PhD dissertation. Oxford University, Oxford.

Delvaux, P., Metens, T., \& Soquet, A. 2002. French Nasal Vowels: Acoustic and Articulatory properties. Proc. $7^{\text {th }}$ ICSLP 1, pp. 53-56.

Hajek, J. and Maeda, S. 2000. Investigating universals of sound change: The effect of vowel height and duration on the development of distinctive nasalization. In Broe, $\mathrm{M}$. Pierrehumbert, J. eds., Papers in Laboratory Phonology V: Acquisition and Lexicon. Cambridge: Cambridge University Press, pp. 52-69. 